\title{
Serum Aspartate Aminotransferase Measurement
}

National Cancer Institute

\section{Source}

National Cancer Institute. Serum Aspartate Aminotransferase Measurement. NCI

Thesaurus. Code C61018.

A quantitative measurement of the amount of aspartate aminotransferase present in a sample of serum. 